\title{
EROSÃO E ACRESÇÃO COSTEIRA NA ENSEADA DOS ANJOS, ARRAIAL DO CABO, RJ
}

\author{
David Canabarro Savi \\ Recebido em 27 setembro, 2005 / Aceito em 27 abril, 2006 \\ Received on September 27, 2005 / Accepted on April 27, 2006
}

ABSTRACT. The present work studies coastal and accretion while morphodynamic implications caused by the construction of a break-water to protect the boats in Porto do Forno, Enseada dos Anjos, Arraial do Cabo, RJ, Brazil. To understand the erosion and accretion caused by the break-water, we analysed previous and later data to its construction such as photography, bathymetric charts, and other information. Corroborating this initial material we carried out many studies as beach profiles, analysis of the coastline changes at different times, study of the balance in plant for inlet beach and waves refraction analysis. The results indicated that the break-water altered several natural processes. They include the distribution of wave gradient through MIKE-21, the sedimentation dynamic by beach profiles, and mainly the localised effects of coastal erosion and accretion perfectly seem in the temporal comparison of photographs, charts and images.

Keywords: coastal erosion, coastal geomorphology, Arraial do Cabo, Rio de Janeiro, Brazil.

RESUMO. 0 presente trabalho estuda a erosão costeira enquanto implicação morfodinâmica causada pela construção de um quebra-mar para a proteção das embarcações no Porto do Forno, Enseada dos Anjos, Arraial do Cabo, RJ, Brasil. Para o entendimento da erosão e acresção ocasionadas pelo quebra-mar foram analisados dados anteriores e posteriores a sua construção como fotos, cartas náuticas e outras informações. Corroborando este material inicial foram realizados vários estudos como: perfis de praia, análise da variação da linha de costa em diferentes épocas, estudo do modelo de equilíbrio em planta para praias de enseada e análise de refração de ondas. Os resultados indicaram que o quebra-mar alterou vários processos naturais. Eles incluem a distribuição da energia de ondas através do MIKE-21, a dinâmica da sedimentação pelos perfis de praia e principalmente os efeitos localizados de erosão e acresção costeira, perfeitamente visualizados na comparação temporal de fotos, cartas e imagem.

Palavras-chave: erosão costeira, geomorfologia costeira, Arraial do Cabo, Rio de Janeiro, Brasil. 


\section{INTRODUÇÃo}

A erosão costeira representa a retirada de sedimentos da costa, a acresção o processo inverso, podendo ser causadas pela variação do nível do mar, variação da fonte de sedimentos, modificações no regime de energias das ondas, ou resposta morfodinâmica às atividades antrópicas como os espigões, quebra-mares e portos (Muehe, 1996).

A construção do quebra-mar do Porto do Forno em Arraial do Cabo (RJ), propiciou maior proteção aos navios e barcos atracados ou fundeados no interior da Enseada dos Anjos. No entanto, esta estrutura somada à construção do próprio porto, alterou, de modo irreversível, a paisagem da enseada e os processos morfodinâmicos, resultando na construção de um enrocamento para proteção da erosão costeira resultante.

Nenhum trabalho geomorfológico feito especificamente sobre a Praia dos Anjos foi encontrado, exceto Silva (1985) que publicou trabalho sobre a sedimentação e morfologia do fundo da plataforma continental interna, nas proximidades da Ilha de Cabo Frio, RJ. Ampliando as áreas de influência, Carvalho (1990) apresentou sua dissertação de mestrado sobre a morfologia e sedimentação interna entre Saquarema e Cabo Frio. Guerra (1992) estudou a margem continental de Cabo Frio. Vários autores estudaram a margem continental brasileira, onde citavam alguns dados sobre a região de Cabo Frio e Arraial do Cabo, por exemplo, Zembruski (1979), e Francisconi et al. (1992). Martin \& Suguio (1989) e Muehe et al. (1989), escreveram sobre a evolução do cordão litorâneo. Turcq et al. (1999) escreveram sobre a evolução das lagoas e cordões arenosos. Klein et al. (2003) escreveu sobre a estabilidade de praias de enseada a partir do uso de programas de modelagem.

0 objetivo do presente trabalho é a avaliação da erosão costeira na enseada dos Anjos em Arraial do Cabo, RJ, utilizando as técnicas da geomorfologia costeira.

\section{Área de estudo}

A cidade de Arraial do Cabo $\left(23^{\circ} 00^{\prime}\right.$ S e $\left.042^{\circ} 00^{\prime} \mathrm{W}\right)$ situada a $165 \mathrm{~km}$ à leste da cidade do Rio de Janeiro. A praia dos Anjos está localizada na enseada dos Anjos, onde pode-se observar um porto, uma marina e um molhe adjacente ao porto (Fig. 1). Esta área tem características peculiares, possui uma enseada restrita, com arco praial de aproximadamente $1200 \mathrm{~m}$ e corda de $1075 \mathrm{~m}$, onde foi construído um quebra-mar de rochas que fecha a entrada da enseada em cerca de 35\% da seção transversal.

A plataforma continental interna é recoberta por areias, com um depocentro lamoso bem caracterizado nas proximidades da
Ilha de Cabo Frio (Saavedra \& Muehe, 1994). Esta região, comparada com as adjacentes à plataforma continental, sofre um pronunciado delgaçamento, perfeitamente visível no comportamento da isóbata de $50 \mathrm{~m}$, e evidenciado pelo fenômeno da ressurgência com a proximidade e mobilidade de volumes de águas profundas - Água Central do Atlântico Sul (ACAS) (DHN, 1985).

A Enseada dos Anjos está inserida no macrocompartimento Bacia de Campos (Muehe, 1998b), subdivisão da região Oriental ou Leste do litoral brasileiro, onde é descrita com ventos predominantes de nordeste, com clima quente, semi-árido (Barbieri, 1984), com trechos de dunas frontais, e areias provenientes da plataforma continental interna. 0 clima de ondas da região é reflexo dos ventos predominantes e do marulho (Saavedra \& Muehe, 1994). A maré na enseada dos Anjos é descrita como assimétrica, semidiurna com desigualdade (CHM/DHN, comunicação verbal). Os registros do marégrafo do Porto do Forno remontam os últimos 18 anos e indicam que o nível do mar, neste período, permaneceu estável. A amplitude de maré é de aproximadamente 1 metro (dados coletados e interpretados pelo IEAPM, constituindo seu arquivo e repassados ao BND0).

\section{METODOLOGIA}

\section{Método de demarcação e levantamento de perfis transversais à praia}

Os perfis de praia foram feitos em 3 diferentes locais: Perfil 1 (Central) localizado fora da sombra do molhe, Perfil 2 (Flanco Sul) local de maior energia e Perfil 3 (Flanco Norte) com menor energia. Determinou-se a orientação de cada perfil, buscando estabelecer uma direção perpendicular à linha de praia. Esta definição foi realizada por meio de aproximações, através da direção geral do escarpamento da pós-praia e do mergulho da face da praia, com o auxílio de bússola. Depois da fixação dos marcos topográficos, realizou-se um nivelamento topográfico, desde 0 reverso do cordão litorâneo até o ponto limite de visada, mar adentro, para a caracterização, tanto da porção emersa do perfil, quanto da praia e porção submersa. Posteriormente foi feito o nivelamento entre os perfis para amarração ao mesmo Datum vertical. Foi utilizado para o nivelamento dos perfis o método expedito descrito por Muehe et al. (2003) e comparado ao registro do marégrafo por nivelamento direto e contra nivelamento (Savi et al., 2003) que ratificou as observações de Muehe et al. (2003) e melhoraram o resultado, introduzindo mais uma correção.

0 levantamento dos perfis foi realizado regularmente, buscando intervalos mensais durante o período de março de 2000 a novembro de 2001, através de nivelamento topográfico e even- 


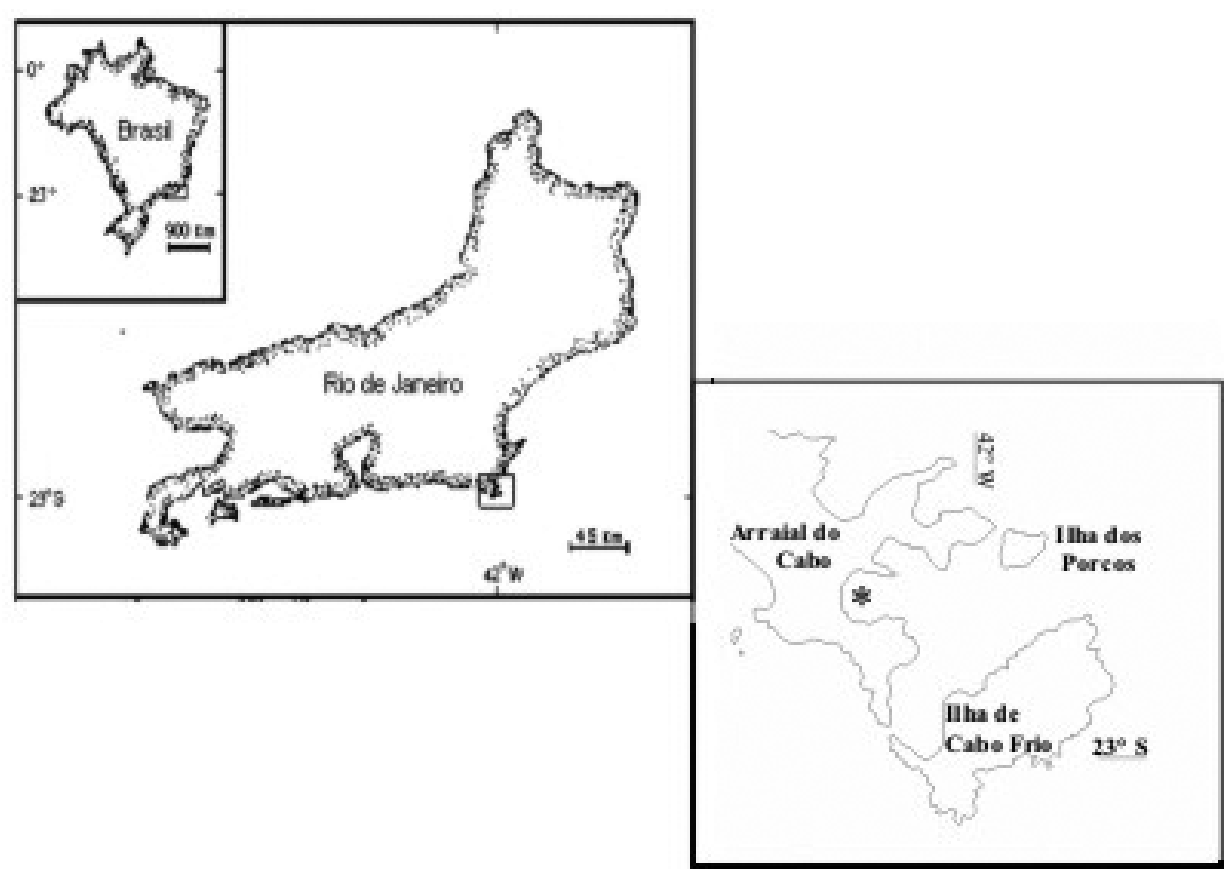

Figura 1 - Área de trabalho recortada do mapa federal e estadual.

tualmente complementado, na praia, pelo método de balizas (Emery, 1961).

\section{Modelo de Equilíbrio em Planta de Praias de Enseada - MEPPE}

0 MEPPE, um software que auxilia no processo de análise do modelo parabólico de equilíbrio das praias de enseada, foi desenvolvido por alunos da Universidade do Vale do Itajaí - SC (Vargas et al., 2002), e se utiliza do modelo parabólico desenvolvido por Hsu et al. (1987), baseando-se em relações entre características geométricas da praia em planta e 0 ângulo de incidência das ondas na praia. Através do modelo parabólico é possível determinar se a praia está em equilíbrio estático ou dinâmico.

\section{Variação da linha de costa}

Foram utilizadas as cartas náuticas 1503 (com escala de 1:20000) dos anos de 1985 e 1995, foto-aérea de 1976 e 2002 na mesma escala das cartas, para a comparação da linha de costa da enseada dos Anjos. A linha de costa de 2002 foi adquirida com GPS para posicionamento cinemático, e superposta às outras figuras, todas georreferenciadas com erro máximo admitido de escala gráfica na ordem de 0,2 mm. Na quantificação da variação da linha de costa, é preciso levar em conta os diferentes momentos de maré, assim as fotos ilustram a variação da linha de costa principalmente na rotação da nova linha, entrando mar adentro no flanco norte e terra adentro no flanco sul. Reduzidas as cotas de marés estimase que no flanco norte houve um engordamento da praia de dez metros na direção do perfil e no flanco sul uma erosão da ordem de quinze metros também na direção do perfil.

\section{Refração de ondas - Modelo MIKE 21}

0 modelo MIKE-21 foi utilizado apenas para os dados de refração de onda, em eventos do quadrante leste, por ser a direção de maior penetração de frente de onda possível $\left(\theta=90^{\circ}\right)$ devido à orientação da enseada. A área utilizada foi restrita à enseada dos Anjos, com ondas de Leste com altura de $2 \mathrm{~m}$, período de $10 \mathrm{~s}$ e espaçamento de $10 \mathrm{~m}$ entre as ortogonais, com resultados mais localizados e na direção de maior efeito sobre a enseada, tendo em vista que, as direções próximas ao Leste (NE) são refratadas e para as demais a enseada é protegida.

\section{RESULTADOS}

\section{Perfis de praia}

Na comparação entre os perfis, pode-se avaliar a diferença de comportamento morfodinâmico ao longo do arco da Praia dos Anjos (Fig. 2). Nesta, os perfis mais expostos Central e flanco Sul apresentaram a partir da profundidade de $3 \mathrm{~m}$ convergência de comportamento. 0 perfil do flanco Sul se apresentou convexo 


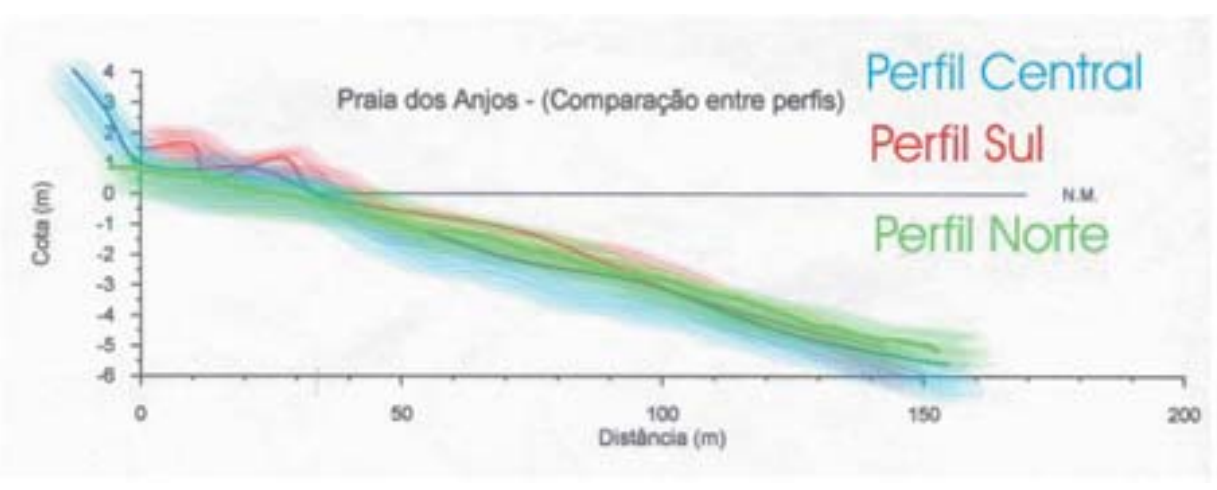

Figura 2 - Envelope (variações medidas) dos três perfis para comparações.

enquanto o perfil Central quase reto, resultando em variação de gradiente não esperada, pois teoricamente, o perfil Central deveria apresentar um gradiente menor que o do flanco Sul, exposto a um ambiente de maior energia (Fig. 2), o perfil norte como mostrado, se apresentou imutável e de baixíssima energia. A própria mutabilidade dos perfis levantados ao longo do tempo reflete o comportamento diferenciado no arco praial, do centro para 0 flanco sul apresenta características intermediárias crescentes em direção ao sul.

Nos levantamentos de campo não foi registrado o transporte longitudinal esperado, mas sim um transporte bidirecional (praiamar), em zig-zag, resultando em acúmulo no flanco norte, como se houvesse uma deriva litorânea para o norte.

\section{Modelo de Equilíbrio em Planta de Praias de Enseada (MEPPE)}

Utilizando o programa de ajuste parabólico (MEPPE) foi gerado um modelo de linha de praia de equilíbrio sem o quebra-mar (Fig. 3A) e outro com o quebra-mar (Fig. 3B). Para o primeiro caso utilizou-se o promontório natural ao norte como ponto de refração de ondas (Fig. 3A), foi obtido um traçado de linha de costa de equilíbrio coincidente com a linha de praia atual. Ao ajustar o modelo pelo quebra-mar como ponto de refração de ondas (Fig. 3B), verificou-se um perfil de equilíbrio diferente da linha de praia atual, terminando a extremidade do perfil de equilíbrio na altura do Porto do Forno, demonstrando o provável desequilíbrio causado pelo quebra-mar.

\section{Variação da linha de costa}

A superposição georreferenciada temporal da linha de praia de 2002 sobre as fotos de 1976 e 1985 mostra claramente a erosão costeira no flanco sul e acresção de sedimentos no flanco norte
(Fig. 4A e B). Quando colocamos as antigas linhas de costa sobre a foto de 2002 (Fig. 4C) podemos observar mais claramente a grande variação que ocorreu com a linha de costa após a construção do quebra-mar e a sua evolução. 0 mesmo foi visto quando utilizamos a carta náutica de 1985 (Fig. 4D).

\section{Refração de ondas}

A simulação da refração de ondas, utilizando o software MIKE-21 mostrou que para um evento de leste com altura de onda de $2 \mathrm{me}$ período de 10s, ocorre uma notável atenuação da onda em direção à praia, chegando a uma altura máxima de 1,4 m na zona central da praia. No flanco sul há uma divergência das ortogonais por conta da soma dos efeitos de batimetria e recorte do costão rochoso, atingindo as ondas uma altura máxima de $1,0 \mathrm{~m}$, enquanto que no flanco norte, devido à presença do molhe ou quebra-mar do Porto do Forno (que estrangula a seção em 36\%), ocorre a difração da frente de onda. Após ultrapassar o molhe em direção ao flanco norte aumenta o espaçamento das ortogonais, variando a altura da onda de $0,8 \mathrm{~m}$ na região mais próxima ao centro do arco e de zero metros no extremo norte do embaiamento (Fig. 5).

\section{DISCUSSÃO}

\section{Perfis topográficos}

Os perfis topográficos demonstraram os efeitos de ventos fortes (NE - agosto a novembro), não acusaram variações devidos a ventos do quadrante Sul. Mostraram ainda, gradação dos efeitos morfodinâmicos ao longo da enseada, isto é, o perfil Sul apresentou invariavelmente as maiores modificações, sendo acompanhado com menor amplitude pelo perfil Central, enquanto o perfil Norte se manteve inalterado na parte submersa, mas registrou em pequena escala, os efeitos dos ventos fortes, na parte emersa (menor amplitude). 

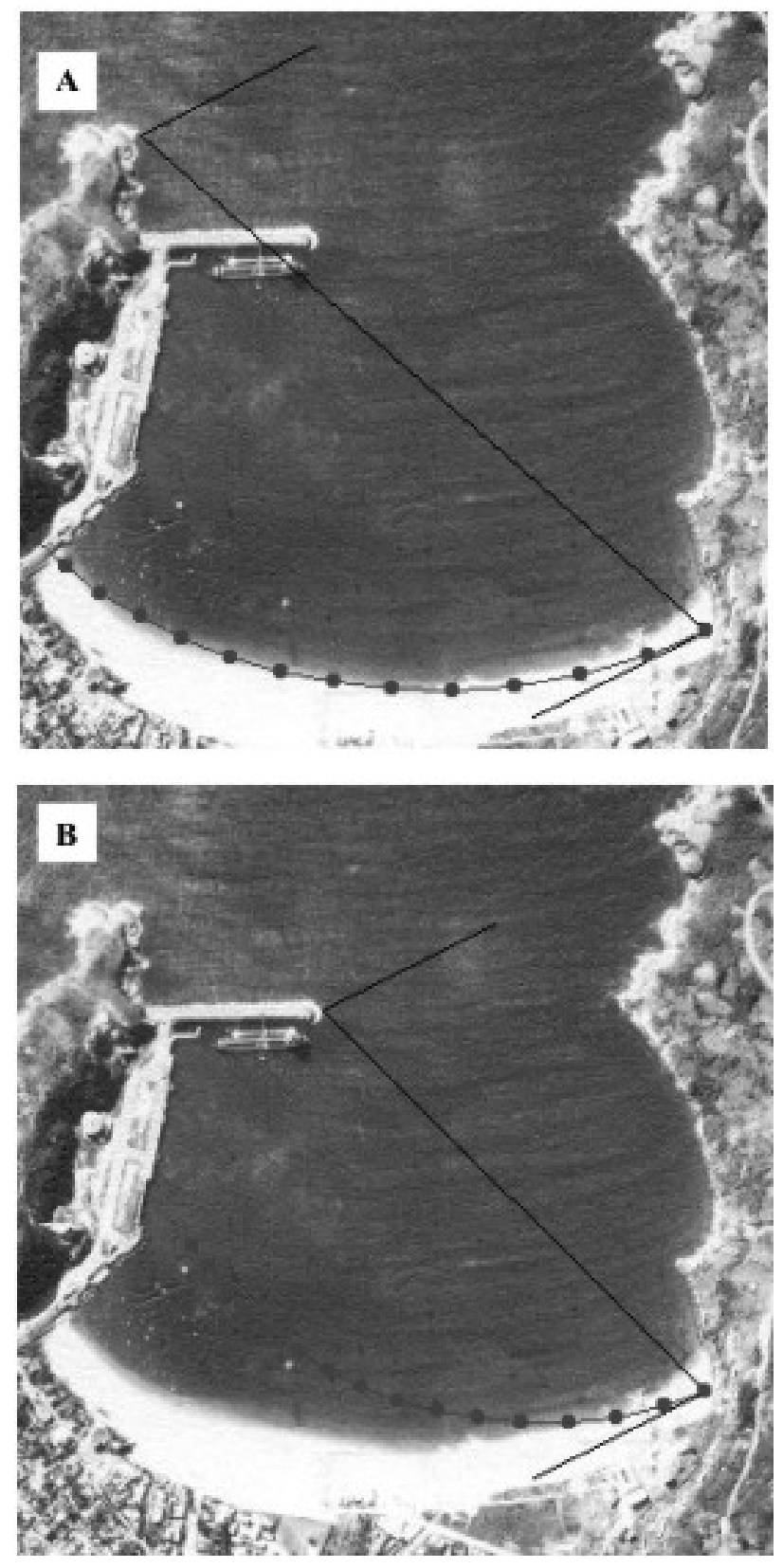

Figura 3 - MEPPE aplicado sem e com a influência do quebra-mar.

As variações dos perfis transversais à praia resultam da energia das ondas a que estes estão submetidos (Muehe, 1996). Segundo Hallermeier (1981), o efeito da sazonalidade sobre os perfis também é variável em seus segmentos, atingindo as maiores amplitudes na parte emersa e diminuindo a amplitude em direção ao mar. Nos locais em que 0 regime de ondas se diferencia em tempo bom (engordamento da praia) e em tempo de tempestade (erosão da praia) há o desenvolvimento de perfis sa- zonais típicos de acumulação e erosão (Shepard, 1954; Muehe, 1998a). Estas variações geralmente ocorrem em períodos cíclicos característicos e isto pôde ser observado também na Praia dos Anjos. Entretanto, os perfis também variaram instantaneamente ao receber a entrada de tormentas do quadrante $\mathrm{NE}$, erodindo a praia, que logo após, retornou ao perfil de tempo bom. Komar (1976) e Muehe (1998a) também descrevem este processo como uma das causas das variações de perfis. 

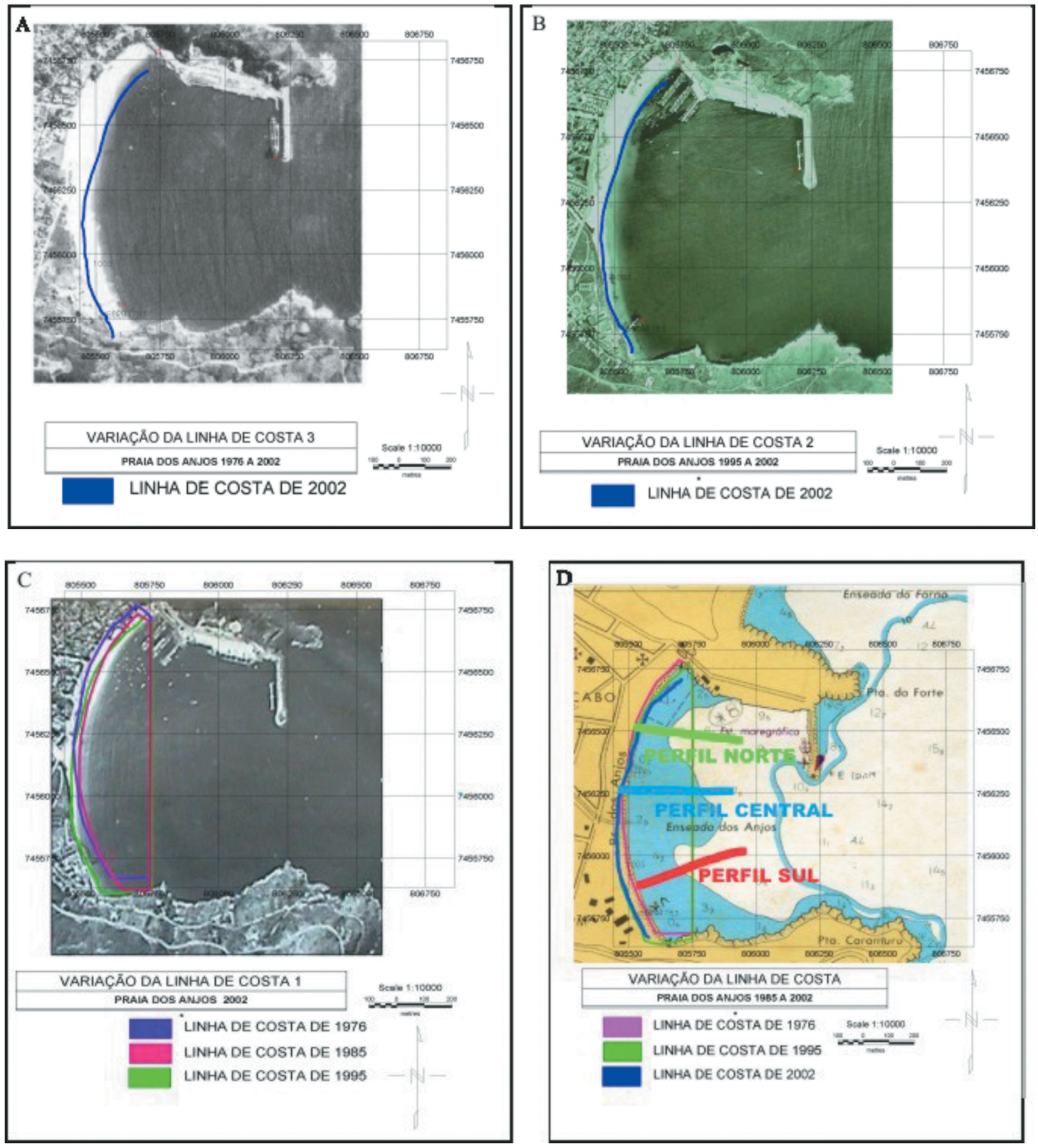

Figura 4 - A e B: Variação da Linha de Costa entre 1976 e 2002 e entre 1995 e 2002. C e D: Variação da Linha de Costa de 2002 com as LC anteriores e LC de 1985 base da Carta Náutica com os perfis plotados em planta e com as outras LC.

A maior variação de volume registrada nos perfis da Praia dos Anjos ocorreu no perfil Sul, com 1 metro de amplitude na parte submersa. Um estudo da variabilidade de perfil realizado na Praia de Ipanema - RJ (Muehe \& Dobereiner, 1977) também registrou variações de acúmulo de sedimento tanto na praia $(2,6 \mathrm{~m})$ quanto na zona de surfe (2,2 m). Ao compararmos os perfis da praia dos
Anjos verifica-se que o flanco Sul ao apresentar tais variações de amplitude indica características de praia intermediária, enquanto o flanco Norte apresenta características de praia refletiva. 0 estado refletivo identifica praias com pouca ou nenhuma zona de surfe, berma da praia elevada e estoque de areia baixo na zona submarina; 0 estado intermediário é caracterizado pela presença 


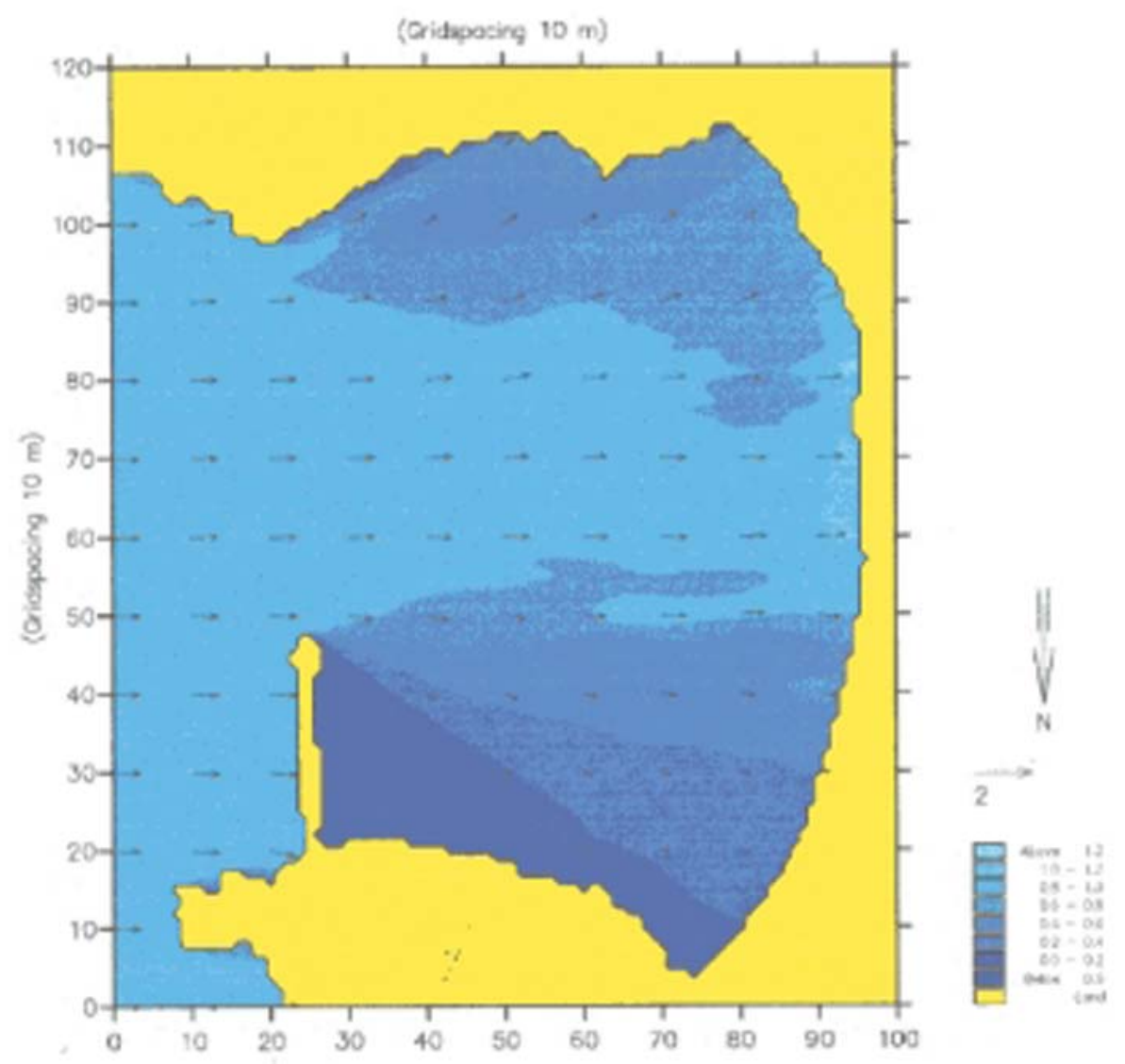

Figura 5 - Modelo de refração MIKE 21 para ondas de Leste.

de bancos e calhas, múltiplas arrebentações e gradiente da face da praia variável (Muehe, 1994).

\section{Modelo de Equilíbrio em Planta para Praias de Enseada}

A utilização do MEPPE na praia dos Anjos corrobora a impressão visual da influência do quebra-mar, onde os resultados apresentados indicam o desequilíbrio ou equilíbrio dinâmico que ocorre na enseada. Ao considerarmos o quebra-mar como ponto de difração das ondas, obtivemos uma linha de costa em equilíbrio dinâmico, tendendo a erosão no sul e acresção no norte da enseada. Ao desconsiderarmos a existência do quebra-mar e utilizarmos a ponta da fortaleza (extremidade do promontório ao norte da enseada) como difrator das ondas, o modelo apresentou uma linha de costa perfeitamente ajustada à existente, demonstrando para esta situação o equilíbrio estático.

A comparação com os demais resultados demonstra a boa aplicabilidade do programa na enseada de estudo, e 0 bom resultado do modelo parabólico (Hsu et al., 1987), além da melhor aplicabilidade do programa.
A erosão do flanco sul da enseada é uma realidade, constatada pelo enrocamento de proteção construído pelo Instituto de Estudos do Mar Almirante Paulo Moreira (IEAPM) naquele local, como pela análise da linha de costa nas fotos mais recentes (Fig. 4).

A foto utilizada para o traçado do MEPPE é de 1976, ao compararmos com a foto de 2002 que inclusive apresenta 0 traçado da linha de costa de 1976 (Fig. 3C), verifica-se a perfeita aplicabilidade do modelo nesta área provando a retrogradação da linha de costa no flanco sul; no entanto em relação ao flanco norte, a taxa de progradação da linha de costa foi menor do que 0 estimado no modelo.

\section{Variação da linha de costa}

A variação da linha de costa com a metodologia proposta a partir da estabilidade do nível médio do mar e da fonte de sedimentos da plataforma continental é evidentemente atribuída a construção interna e expansão do quebra-mar que data da mesma época da construção do enrocamento para proteção do (IEAPM). 


\section{Refração de ondas}

0 modelo MIKE-21 ratifica o efeito de sombra causado pelo quebra-mar na difração da frente de onda, e a atenuação da altura da onda resultante no flanco Norte, tendo em sua extremidade altura significativa próxima de zero. Simultaneamente demonstra a concentração da energia de ondas, refletida nas suas alturas significativas que atingem 0 ápice do centro para o centro-sul do arco praial.

\section{CONCLUSÃO}

- Os perfis topográficos transversais à praia caracterizaram um arco praial com comportamento morfodinâmico variável da extremidade Norte à extremidade Sul, com a praia ora respondendo como totalmente refletiva, ora refletiva ao Norte e intermediária ao Sul.

- 0 modelo de equilíbrio em planta para praia de enseada indicou que a enseada se encontra em equilíbrio dinâmico, tendendo a erodir o flanco Sul e assorear o flanco Norte.

- A metodologia usada para comparação da variação da linha de costa entre os diferentes anos corroborou com os resultados apresentados pelas outras técnicas de geomorfologia, demonstrando ser um método eficiente para este tipo de análise.

- A refração de ondas mostrou a interferência do quebramar na distribuição da energia da onda na enseada, e sua concentração no centro e flanco Sul.

\section{AGRADECIMENTOS}

A DHN e IEAPM pelo apoio institucional oferecido ao autor. Ao Prof. Dr. Dieter Muehe pela orientação durante o mestrado, do qual derivou este trabalho. As doutorandas Ivanise Maria Wolff e Laís V. Ramalho pela revisão do manuscrito e figuras.

\section{REFERÊNCIAS}

BARBIERI EB. 1984. Cabo Frio e lguaba Grande, dois microclimas distintos a um curto intervalo espacial. In: LACERDA LD de, ARAÚJO DSD de, CERQUEIRA R \& TURCQ BC. Restingas: Origem, Estrutura, Processos. Niterói: UFF, p. 3-12.

CARVALHO VMSG de. 1990. Morfologia e sedimentação da plataforma continental interna entre Saquarema e Cabo Frio - RJ. Dissertação (Mestrado em Geografia) - Instituto de Geociências, UFRJ, Rio de Janeiro. $90 \mathrm{p}$.

DHN. DIRETORIA DE HIDROGRAFIA E NAVEGAÇÃO. 1985. Atlas oceanográfico - Atlântico Sul, Costa Sudeste do Brasil, v.1.
EMERY K0. 1961. A simple method of measuring beach profiles. Limnology and Oceanography, 6: 90-93.

FRANCISCONI O, LEYDEN R \& KOWSMANN RO. 1992. Arcabouço estrutural preliminar da margem continental sul brasileira. Rio de Janeiro: CPRM, 32 p. (Relatório CPRM).

GUERRA JV. 1992. Minerais pesados como indicadores de paleodrenagem e direção de transporte de sedimentos na plataforma continental interna entre Saquarema e Arraial do Cabo, RJ. Dissertação (Mestrado em Geografia) - Instituto de Geociências, UFRJ, Rio de Janeiro. 104 p.

HALLERMEIER RJ. 1981. A profile zonation for seasonal sand beaches from wave climate. Coastal Engineering, Amsterdam, 4: 253-277.

HSU JRC, SILVESTER R \& XIA YM. 1987. New characteristics of equilibrium-shaped bays. In: Conference on Coastal and Oceanic Engineering, 8, Australia. Proceedings $8^{\text {th }}$ Australia Conference on Coastal and Oceanic Engineering, Australia, p. 140-144.

KLEIN AHF, VARGAS A, RAABE ALA \& HSU JRC. 2003. Visual assessment of bayed beach stability using computer software. Computer and Geosciences, 29: 1249-1257.

KOMAR PD. 1976. Beach process and sedimentation. New Jersey: Prentice-Hall, $429 \mathrm{p}$.

MARTIN L \& SUGUIO K. 1989. Excursion route along the brazilian coast between Santos (State of São Paulo) and Campos (North of State of Rio de Janeiro). In: International Symposium on global changes in South America during the quaternary. São Paulo. Proceedings of International Symposium on global changes in South America during the quaternary. São Paulo: INQUA. 1989. 2: 68-121.

MUEHE D. 1994. Lagoa de Araruama: Geomorfologia e sedimentação. Caderno de Geociências, 10: 53-62.

MUEHE D. 1996. Geomorfologia costeira. In: CUNHA SB da \& GUERRA AJT. Geomorfologia: exercícios, técnicas e aplicações. Rio de Janeiro: Bertrand Brasil, p: 191-238.

MUEHE D. 1998a. Estado morfodinâmico praial no instante da observação: uma alternativa de identificação. Revista Brasileira de Oceanografia, Rio de Janeiro, 46 (2): 157-169.

MUEHE D. 1998b. 0 litoral brasileiro e sua compartimentação. In: CUNHA SB da \& GUERRA AJT. Geomorfologia do Brasil. Rio de Janeiro: Bertrand Brasil, p: 273-349.

MUEHE D \& DOBEREINER C. 1977. Dinâmica do fundo marinho ao longo do pier de Ipanema, Rio de Janeiro. Anais da Academia Brasileira de Ciências, Rio de Janeiro, 49(2): 281-285.

MUEHE D, CORRÊA CHT \& IGNARRA SMN. 1989. Avaliação dos riscos de erosão dos cordões litorâneos entre Niterói e Cabo Frio. In: Simpósio de Geografia Aplicada. 3. Anais do $3^{\circ}$ Simpósio de Geografia Aplicada. Nova, p: 368-383. 
MUEHE D, ROSO RH \& SAVI DC. 2003. Avaliação de método expedito de determinação do nível do mar como datum vertical para amarração de perfis de praia. Revista Brasileira de Geomorfologia, 4(1): 53-57.

SAAVEDRA LBF \& MUEHE D. 1994. Dinâmica sedimentar da plataforma continental interna entre a llha de Cabo Frio e o Cabo Búzios, RJ. In: Congresso Brasileiro de Geologia - Anais do $36^{\circ}$ Congresso Brasileiro de Geologia, 1: 370-371.

SAVI DC, ROMANO RCG, SILVA NETO PF \& RIBEIRO RCS. 2003. Reavaliação do Método Expedito de Determinação do Nível Médio do Mar. Anais do V Encontro de Ondas e Marés.

SHEPARD FP. 1954. Nomenclature based on sand-silt-clay ratios. Journal of Sedimentary Petrology, 13: 79-81.

SILVA AC da. 1985. Sedimentação e morfologia do fundo da plataforma continental interna nas proximidades da Ilha do Cabo Frio, RJ. Dissertação (Mestrado em Geografia) - Instituto de Geociências, UFRJ,
Rio de Janeiro. 189 p.

TURCQ B, MARTIN L, FLEXOR JM, SUGUIO K, PIERRE C \& TASAYACOORTEGA L. 1999. Origin and evolution of the quaternary coastal plain between Guaratiba and Cabo Frio, State of Rio de Janeiro, Brazil. Environmental Geochemistry of Coastal Lagoon Systems. Rio de Janeiro, 6: 25-46.

VARGAS A, RAABE ALA \& KLEIN AHF. 2002. Software Educacional para Auxílio na Aplicação e Aprendizagem do Modelo Parabólico de Praias de Enseada. Revista Brasileira de Geomorfologia, 3(1): 11-20.

ZEMBRUSKI SG. 1979. Geomorfologia da margem continental sul brasileira e das bacias oceânicas adjacentes. In: Geomorfologia da margem continental brasileira e das áreas oceânicas adjacentes. Rio de Janeiro, PETROBRAS, CENPES, DINTEP, 177 p. Série Projeto REMAC, 7: 129-177.

\section{NOTA SOBRE $O$ AUTOR}

David Canabarro Savi. Oficial superior da Marinha do Brasil, pós-graduado em Hidrografia na Diretoria de Hidrografia e Navegação, Mestre em Geociências pela Universidade Federal do Rio de Janeiro na área de Geomorfologia Costeira. É formado em Comércio Exterior pela Universidade do Vale dos Sinos (RS), estudou geologia na Universidade Federal do Rio Grande do Sul, trabalhou dois anos no navio geofísico Almirante Câmara, tendo participado de três comissões LEPLAC. Atualmente é encarregado da Divisão de Geologia do Instituto de Estudos do Mar Almirante Paulo Moreira. 